\title{
The effect of heat treatment and impact angle on the erosion behavior of nickel-tungsten carbide cold spray coating using response surface methodology
}

\author{
Marios Kazasidis $^{1}{ }^{1} \cdot$ Elisa Verna ${ }^{2} \cdot$ Shuo Yin $^{1} \cdot$ Rocco Lupoi $^{1}$
}

Received: 29 April 2021 / Accepted: 21 July 2021 / Published online: 10 August 2021

(C) The Author(s) 2021

\begin{abstract}
This study elucidates the performance of cold-sprayed tungsten carbide-nickel coating against solid particle impingement erosion using alumina (corundum) particles. After the coating fabrication, part of the specimens followed two different annealing heat treatment cycles with peak temperatures of $600{ }^{\circ} \mathrm{C}$ and $800{ }^{\circ} \mathrm{C}$. The coatings were examined in terms of microstructure in the as-sprayed (AS) and the two heat-treated conditions (HT1, HT2). Subsequently, the erosion tests were carried out using design of experiments with two control factors and two replicate measurements in each case. The effect of the heat treatment on the mass loss of the coatings was investigated at the three levels (AS, HT1, HT2), as well as the impact angle of the erodents $\left(30^{\circ}, 60^{\circ}, 90^{\circ}\right)$. Finally, the response surface methodology (RSM) was applied to analyze and optimize the results, building the mathematical models that relate the significant variables and their interactions to the output response (mass loss) for each coating condition. The obtained results demonstrated that erosion minimization was achieved when the coating was heat treated at $600{ }^{\circ} \mathrm{C}$ and the angle was $90^{\circ}$.
\end{abstract}

\section{Introduction}

Cold spray is an additive manufacturing process characterized by high deposition rate of mass[1-3], and low thermal stresses[4], while it can efficiently fabricate dense and thick metallic coatings[5]. It can also be used to deposit metal matrix composites that consist of a metal matrix and ceramic reinforcement, also known with the term of "cermets"[6]. A well-known group of cermet materials are the cemented carbides[7] that specifically refer to composites with nickel or cobalt matrix and tungsten carbide reinforcement [7, 8].

The application of cold-sprayed cermet coatings on metallic materials has been proven to be effective for the prevention of substrate degradation due to corrosion[9],

Marios Kazasidis

marios_kazasidis@hotmail.com; kazaside@tcd.ie

$\triangle$ Rocco Lupoi

lupoir@tcd.ie

1 Department of Mechanical, Manufacturing \& Biomedical Engineering, Trinity College Dublin, The University of Dublin, Parsons Building, Dublin 2, Ireland

2 Department of Management and Production Engineering, Politecnico Di Torino, Corso Duca degli Abruzzi 24, 10129 Turin, Italy wear[10, 11], and erosion phenomena[12] in many cases. Couto et al.[13] investigated the electrochemical properties of WC-Co cold spray coating under an extremely corrosive environment. Their research concluded that the coating with WC-12Co feedstock powder provided the highest corrosion resistance against electrochemical corrosion due to the reduction of the cobalt retention in the final coating and the resulting abatement of the electrolyte penetration into the WC/Co interface. Triantou et al.[14] investigated the effect of alumina addition on the sliding wear resistance of copper coatings, reporting micro-abrasion and micro-ploughing as the main wear mechanisms. They also concluded that the presence of $\mathrm{Al}_{2} \mathrm{O}_{3}$, especially when consolidated in small particle sizes $(2-12 \mu \mathrm{m})$, acts beneficiary in terms of mass loss reduction. Yin et al.[15] cold sprayed ternary mixtures of feedstock powder that comprised $\mathrm{Ni}$, and composite porous WC-17Co powder, reporting an enhanced wear resistance for the coatings with high WC retention. Their research also mentioned that the dominant wear mechanism for coatings with WC retention less than $65 \mathrm{wt}$.\% was lowcycle surface fatigue that was accompanied by the formation of a tribofilm. The lowest wear rate was observed in the highest content of tungsten carbide, resulting from the sliding of the counterpart on the protruding ceramic particles. Krebs et al.[16] cold sprayed Cu-Al-Bronze coatings 
to enhance the cavitation erosion performance of the shipbuilding GL-A steel used in the manufacturing of ship rudders. They utilized feedstock powders in as-gas atomized and annealed states, showing that the annealing at $600{ }^{\circ} \mathrm{C}$ for $7 \mathrm{~h}$ resulted in coatings with minimal porosity and erosion rate. They finally concluded that the overall performance of the cold-sprayed coatings was superior compared to the steel substrate. Despite being widely reported as beneficial in terms of resistance against material removal, cold-sprayed cermets do not indicate superior erosion and wear properties in all cases compared to bulk metallic materials[17], and therefore, each case should be examined individually.

The current study focuses on the prevention of the solid particle erosion (SPE) of duplex stainless steel, a promising material for applications such as pressure vessels and underwater pipelines[18] that necessitate high resistance against degradation occurred by the impingement of solid particles. In general, SPE has been encountered in the relevant literature following various approaches such as the modification of the machinery design, the use of filtration systems, or the adjustment of pressure regulators. From the perspective of materials science, many researchers attempted to address SPE of metals with the fabrication of coatings[19] using methods such as laser cladding[8], plasma spray[20, 21], and high-velocity oxyfuel[22] spray. The authors dealt with the aforementioned problem by applying cold-sprayed composite coatings with nickel matrix and tungsten carbide reinforcement, emphasizing the effect of heat treatment on the erosion resistance of the coatings. Relevant research is limited and has been mainly carried out by Alidokht et al. in two publications. In their first publication[23], they used pure cold-sprayed $\mathrm{Ni}$ as a reference. The obtained results showed that the composite coating resulted from separate $\mathrm{Ni}$ and WC powders presented similar SPE resistance to $\mathrm{Ni}$ coating under an impact angle of $30^{\circ}$ and lower SPE resistance at $90^{\circ}$. They attributed the overall inferior cermet performance to the low WC content (10 vol.\%) and the weak bonding between nickel and tungsten carbide particles that had median diameters (d50) of $7 \mu \mathrm{m}$ and $30 \mu \mathrm{m}$, respectively. The hardness of both coatings was found to be at the same level, in the order of $370 \mathrm{HV}$. The same author[24] investigated the SPE of Ni-WC coatings using agglomerated and sintered WC/Ni powders with the addition of extra nickel as a binder phase in various percentages. The erosion tests were also executed at $30^{\circ}$ and $90^{\circ}$, revealing that while $\mathrm{Ni}$ matrices control the erosion resistance at low WC contents, a higher concentration of WC/Ni particles (WC retention above $40 \mathrm{vol} . \%$ ) due to the presence of the ductile $\mathrm{Ni}$ shell and the enhanced bonding of WC into the matrix reduced the erosion rate at oblique impact angles.

The complex nature of the SPE mechanism involves several variables and their interactions with the particle properties (e.g., feed rate, velocity, size, hardness), and the impingement angle to be the predominant ones[7, 25-27]. Meanwhile, the intrinsic properties of the materials have been reported to inverse the effect of the variables on the erosion resistance. For instance, ductile materials exhibit better erosion resistance at high impingement angles (close to $90^{\circ}$ ), while brittle materials at oblique angles (closer to $\left.0^{\circ}\right)[7,28]$. As a result, the identification of a standard method for predicting indirectly the erosion performance of coatings is extremely difficult $[27,28]$. To this end, one of the most widely adopted techniques to assess the effect of control variables on the coating erosion resistance is the design of experiments (DOE)[29]. Studies over the past years have provided new insights on the understanding using DOE methodology. It has been applied for the investigation of the erosion resistance of coatings produced through thermal spray technologies such as high-velocity oxyfuel[25, 30], plasma spray[31], arc ion plating[32], and filtered cathodic vacuum arc technique[33]. Nevertheless, few empirical studies have investigated the erosion performance of cold spray coatings through experimental design[34], which is a major innovative aspect of the present publication.

The authors applied DoE and response surface methodology (RSM) to achieve mass loss optimization. Regarding the erosion process, the parameters under investigation were the impingement angle (angle between the erodent velocity and the coating surface), and the coating conditions (assprayed and two different annealing cycles) were examined. The authors developed the mathematical model that relates the significant variables and their interactions to the output response, i.e., mass loss, separately for the three coating conditions. The coatings were examined in terms of microstructure and microhardness relating these properties with their erosion performance. Finally, the erosion mechanisms were revealed using stereoscopy, and optical, digital, and scanning electron microscopy.

\section{Experimental methodology}

\subsection{Materials and cold spray process}

The feedstock of the cold spray process was binary and consisted of $\mathrm{Ni}(-45 /+16 \mu \mathrm{m}$, Praxair), and the agglomerated and sintered WC/Ni $(-45 /+15 \mu \mathrm{m}$, Flame Spray Technologies). The two powders were mechanically mixed at a 1:4.5 (Ni-WC/Ni) mass ratio. The feedstock was fed into a custom-made cold spray system (Trinity College Dublin, Ireland) through a powder hopper (PF100WL, Uniquecoat Technologies LLC, USA), with a rate of $80 \mathrm{~g} / \mathrm{min}$, and was subsequently sprayed on the as-machined surface of 316 stainless steel plates $4 \mathrm{~mm}$ thick.

Nitrogen was used as propellant gas at a pressure of 3.0 $\mathrm{MPa}$ and preheating temperature of $850{ }^{\circ} \mathrm{C}$. The particles 
were accelerated towards the substrate through a WC-Co De Laval nozzle with a divergent length of $190 \mathrm{~mm}$, throat diameter of $3 \mathrm{~mm}$, and outlet diameter of $8 \mathrm{~mm}$. Its standoff distance and transversal velocity during the spraying process were set at $40 \mathrm{~mm}$ and $25 \mathrm{~mm} / \mathrm{s}$ respectively. The selected building strategy followed a zig-zag pattern in two passes and resulted in a coating thickness of approximately $1.4 \mathrm{~mm}$.

\subsection{Material characterization}

The particle size distributions of the feedstock powders and the alumina erodents were analyzed using a Mastersizer 2000 laser diffraction particle size analyzer (Trinity College, Ireland). After the cold spray process, specimens of appropriate dimensions were extracted from the coatings and mounted into a conductive resin to be subjected to standard metallographic techniques for microstructure observation. The cross sections of the specimens were examined in aspolished and etched (Kalling's reagent) conditions using an optical microscope and a scanning electron microscope (SEM, Carl Zeiss UTRA, CRANN). The calculation of the average porosity and WC retention in the coatings was performed with ImageJ analysis software by analyzing five optical micrographs taken from the middle of the coating thickness with $\mathrm{a} \times 500$ magnification. For assessing the heat treatment effect of the coating properties, their microhardness in the as-sprayed and the heat-treated conditions was estimated after ten repetitions, using a Vickers microhardness tester (Mitutoyo MVK-H1, Japan). Finally, the characteristics of the erosion were revealed in macro and micro scale using a digital camera, a digital microscope (Olympus DSX1000, CRANN), and the scanning electron microscope.

\subsection{Heat treatment and erosion testing}

A full factorial design was adopted for the execution of the SPE tests. In this paper, the selected control factors were the impact angle and the state of the coating. Rectangular specimens with dimensions of $45 \times 25 \mathrm{~mm}$ [2] were extracted from the cold-sprayed plates, milled on the top surface until the final thickness of the cold-sprayed coating was approximately $1.0 \mathrm{~mm}$. Six specimens were annealed in vacuum, at $600{ }^{\circ} \mathrm{C}$ for $1 \mathrm{~h}$, using a ramp rate of $10{ }^{\circ} \mathrm{C} / \mathrm{min}$ and a slow cooling at the end of the process. The other six specimens followed a similar heat treatment process with a holding temperature at $800{ }^{\circ} \mathrm{C}$. The conditions of the coatings were designated HT1 and HT2 respectively for the former and the latter batch of specimens. The levels of the control factors used in the DOE are listed in Table 1.

In total, eighteen $\left(2 \cdot 3^{2}\right)$ erosion tests were executed, as the design was replicated twice to improve the accuracy of the predicted results. The experiments were randomized, as shown in Table 2. After the erosion experiments, the
Table 1 The control factors' levels used in the planned experimentation

\begin{tabular}{ll}
\hline Control factors & Levels \\
\hline Impact angle, $\alpha\left(^{\circ}\right)$ & $30-60-90$ \\
Condition of coating, C & AS-HT1-HT2 \\
\hline
\end{tabular}

accumulative mass loss was used as the response to evaluate coatings' performance. The aggregated results were statistically analyzed using the RSM[35] implemented with the MINITAB $®$ software. After developing the mathematical models that predict the mass loss of the cold-sprayed coating in each condition, an experimental validation was performed to verify the adequacy of such prediction models. In detail, three additional test runs were executed at an angle of $45^{\circ}$ that lies within the range of working limits and differs from the values of Table 2.

The experimental setup of the SPE test is illustrated in Fig. 1. The particles of alumina erodents were supplied into the system through a hopper, subsequently dragged by compressed air of $0.3 \mathrm{MPa}$, and finally injected axially through the nozzle. The cold-sprayed specimens were placed into the sample holder of adjustable angle and a standoff distance of $20 \mathrm{~mm}$. The duration of each SPE test was $10 \mathrm{~min}$.

\section{Results and discussion}

\subsection{Powder characterization}

The composite agglomerated and sintered powder consisted of nanostructured WC particles (Fig. 2a). These particles were embedded into a porous pure nickel matrix, which has been reported to facilitate their consolidation on the final coating[24]. Ni powder (Fig. 2b) attained spherical morphology with some dispersed agglomerations, while alumina particles had an angular shape (Fig. 2c.) As it is indicatively depicted in the insets of Fig. 2a and b, the composite powder has a porous cross section, while Ni particles are compact. The particle size distribution for each powder is shown in Fig. 2 d. The median diameters were found to be $40 \mu \mathrm{m}$, $29 \mu \mathrm{m}$, and $120 \mu \mathrm{m}$ for the $\mathrm{WC} / \mathrm{Ni}, \mathrm{Ni}$, and alumina powders, respectively. As a result, it can be stated that during the erosion testing, the particles of the erodents are highly likely to impinge on more than one coating particles depending on the orientation of the erodent at the moment of the impact.

\subsection{Microstructural characterization of the coatings}

The as-polished surfaces of the cold-sprayed coatings in the as-sprayed and the two heat-treated conditions are indicatively presented in Fig. 3.

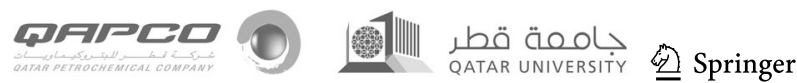


Table 2 Full factorial design (FFD) table of the SPE tests

Fig. 1 The experimental setup of the solid particle erosion testing

\begin{tabular}{llllllllll}
\hline Run order & 1,18 & 2,13 & 3,14 & 4,11 & 5,9 & 6,15 & 7,10 & 8,17 & 12,16 \\
\hline$\alpha\left(^{\circ}\right)$ & 30 & 90 & 90 & 60 & 30 & 60 & 90 & 60 & 30 \\
C & AS & HT1 & HT2 & AS & HT2 & HT1 & AS & HT2 & HT1 \\
\hline
\end{tabular}

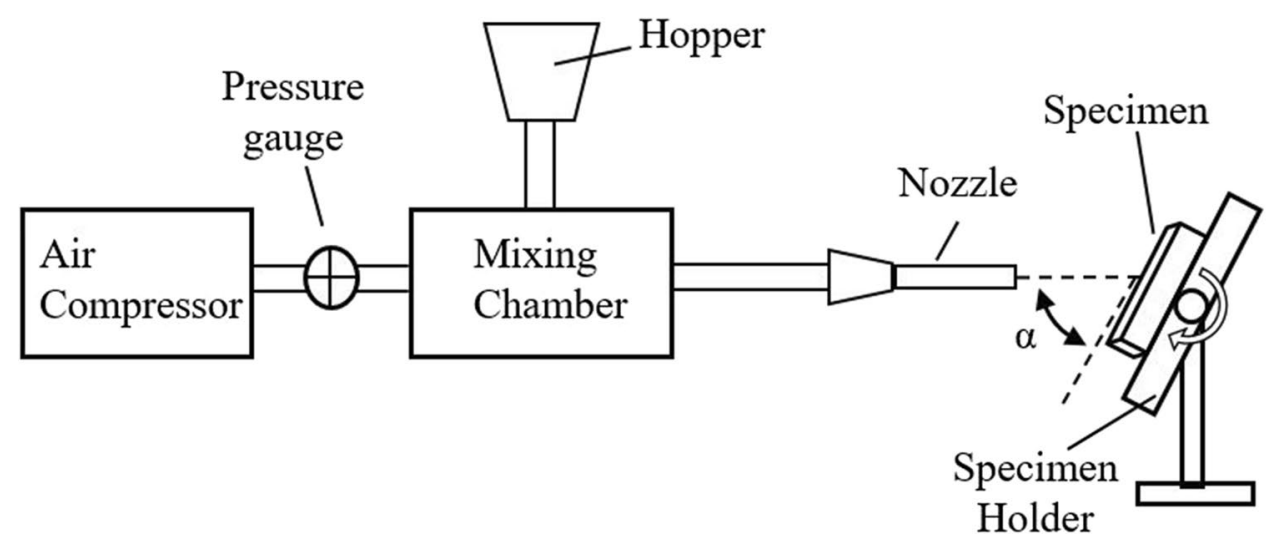

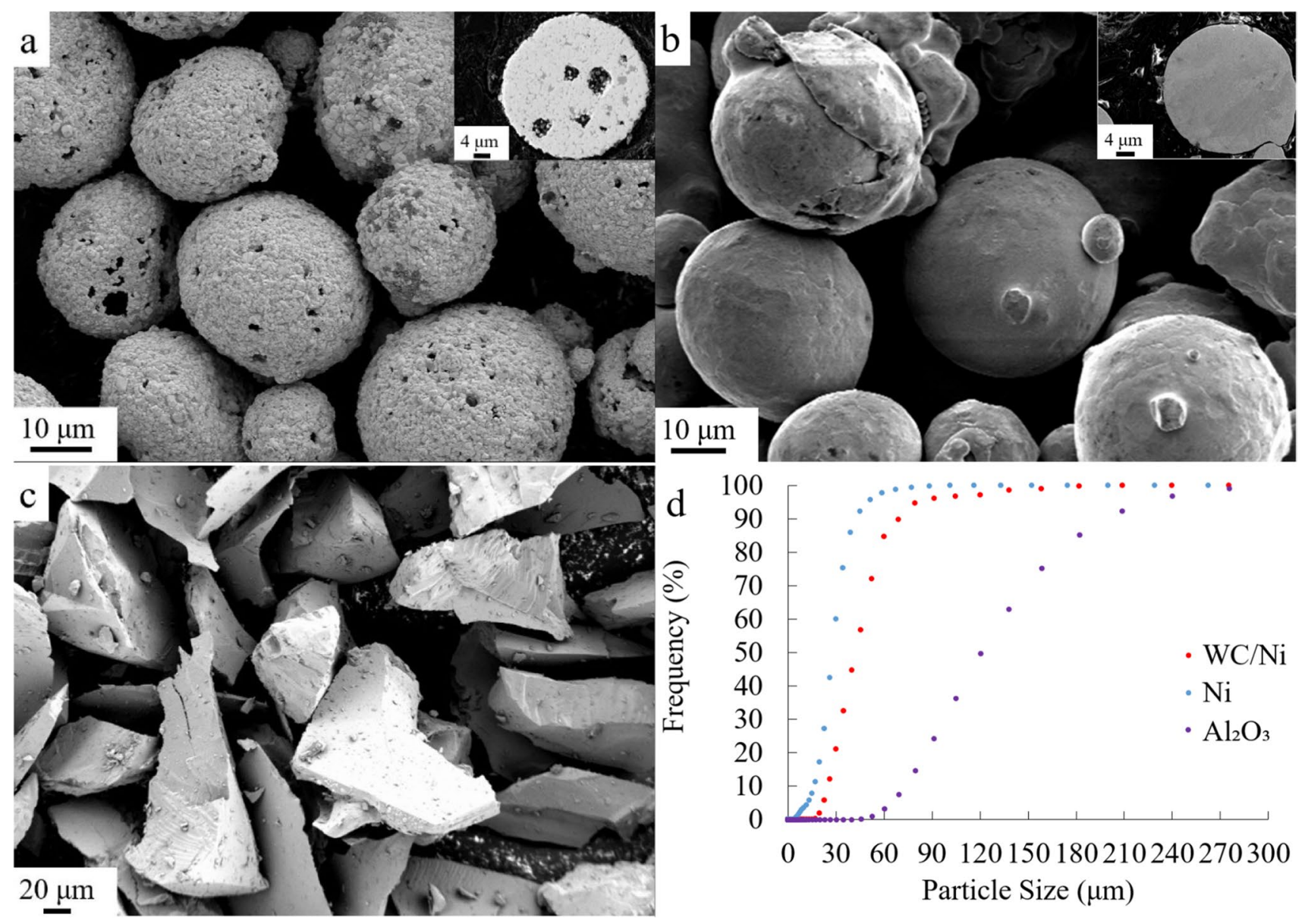

Fig. 2 Electron micrographs of the feedstock powders. a Composite WC/Ni powder. b Nickel powder. c Alumina erodent particles. d Particle size distribution of the $\mathrm{WC} / \mathrm{Ni}, \mathrm{Ni}$, and $\mathrm{Al}_{2} \mathrm{O}_{3}$ powders
Springer
घना
(1) |짗|||||||
جطامعة قطر 


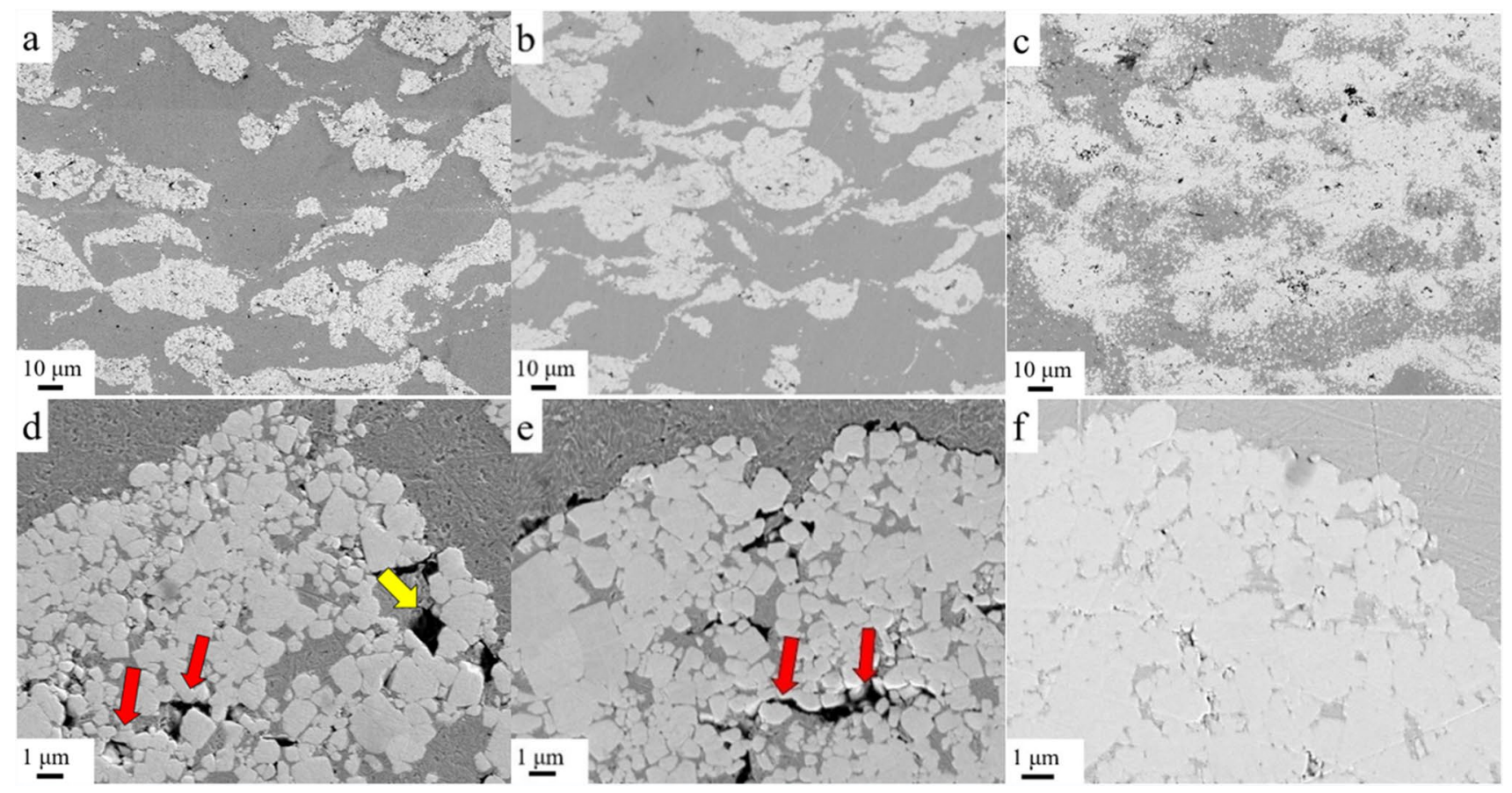

Fig. 3 Electron micrographs of the as polished cold-sprayed composite coatings in the various conditions. a, d As-sprayed. b, e HT1. c, f HT2

The distinct areas of the coating, i.e., carbide particles, nickel matrix, and porosity, attain white, grey, and black color, respectively. Concerning the tungsten carbide percentage, it was measured at $46 \pm 8 \mathrm{vol} . \%, 51 \pm 7 \mathrm{vol} . \%$, and $52 \pm 8 \mathrm{vol} \%$, for the coatings in AS, HT1, and HT2 conditions respectively. These results indicate a slightly higher retention than that reported by Melendez et al.[36], who utilized sintered WC powder embedded in a cobalt matrix with similar WC level in the initial feedstock. The obtained significant variation of the WC content among the micrographs of a specific coating is indicated by the high standard deviation values. This has also been reported by Alidokht et al.[37] and Peat et al.[38]. It can be attributed mainly to the mechanical blending of the powders, which cannot always ensure the highest uniformity in the coating[39]. In Fig. 3d and e, the formation of cracks and pores can also be observed as shown with red arrows, while in Fig. 3d, the yellow arrow demonstrates the detachment of a WC particle due to its poor bonding with the surrounding matrix. Moreover, as indicated in Fig. 3f, the coherency of HT2 coating seems to be enhanced with fewer discontinuities than the other two conditions.

Comparing the cross section of the composite powder as indicatively shown in Fig. 2a with the as-sprayed coating (Fig. 3a), cold spray process seems to eliminate porosity due to the high kinetic energy of the particles and the yielding of the ductile nickel. In quantitative terms, the porosity of the coldsprayed coatings was found to be $5.2 \pm 1.6 \mathrm{vol} . \%, 3.2 \pm 2 \mathrm{vol} . \%$, and $0.3 \pm 0.1 \mathrm{vol} . \%$ for the as-sprayed, HT1, and HT2 conditions respectively. Moreover, the porosity variation among the samples indicates that the selected annealing strategy contributed to the reduction of porosity of the cold-sprayed coating. The beneficial effect of the heat treatment on the coating porosity was also highlighted by Tang et al.[40], who reported a decrease from above $1.7 \%$ to below $0.5 \%$ when annealed Ti-WC cermet at $650{ }^{\circ} \mathrm{C}$ for $1 \mathrm{~h}$ and argon atmosphere. On the contrary, Sun et al.[41] reported an unaltered porosity level of Inconel 718 cold-sprayed coatings after furnace heat treatment in vacuum at $900{ }^{\circ} \mathrm{C}$ for $10 \mathrm{~min}$. Similarly, Wong et al.[42] reported that annealing for $2 \mathrm{~h}$ under shielding atmosphere at lower temperatures $\left(950^{\circ} \mathrm{C}, 1010^{\circ} \mathrm{C}\right.$, and $\left.1060^{\circ} \mathrm{C}\right)$ than those that Levasseur investigated[43] did not result in porosity change in cold-sprayed Inconel 718 coatings. As a result, it can be stated that the annealing effect on the reduction of porosity may depend mainly on the type of the material, the heat treatment method, the holding temperature, and the holding time. In the case of cemented carbides, as investigated in the framework of the present study, the selected annealing strategy seems to lead to densification of the coating, which resulted from the atomic diffusion and mass rearrangement across the inter-particle interfaces.

After etching, the contours of the nickel and tungsten carbide particles became more prominent, as shown in Fig. 4. Light grey, grey, and dark grey areas represent $\mathrm{Ni}, \mathrm{WC}$, and pores respectively. The composite nickel-tungsten carbide powder consolidates in the resulted coatings as intact (Fig. 4a, h), partially fractured (Fig. 4b, white arrow), and entirely fractured particles that may attain a necklace-like structure which accumulates along intersplat boundaries (Fig. $4 \mathrm{~d}$ and e, white arrows).

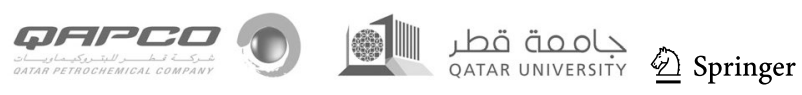




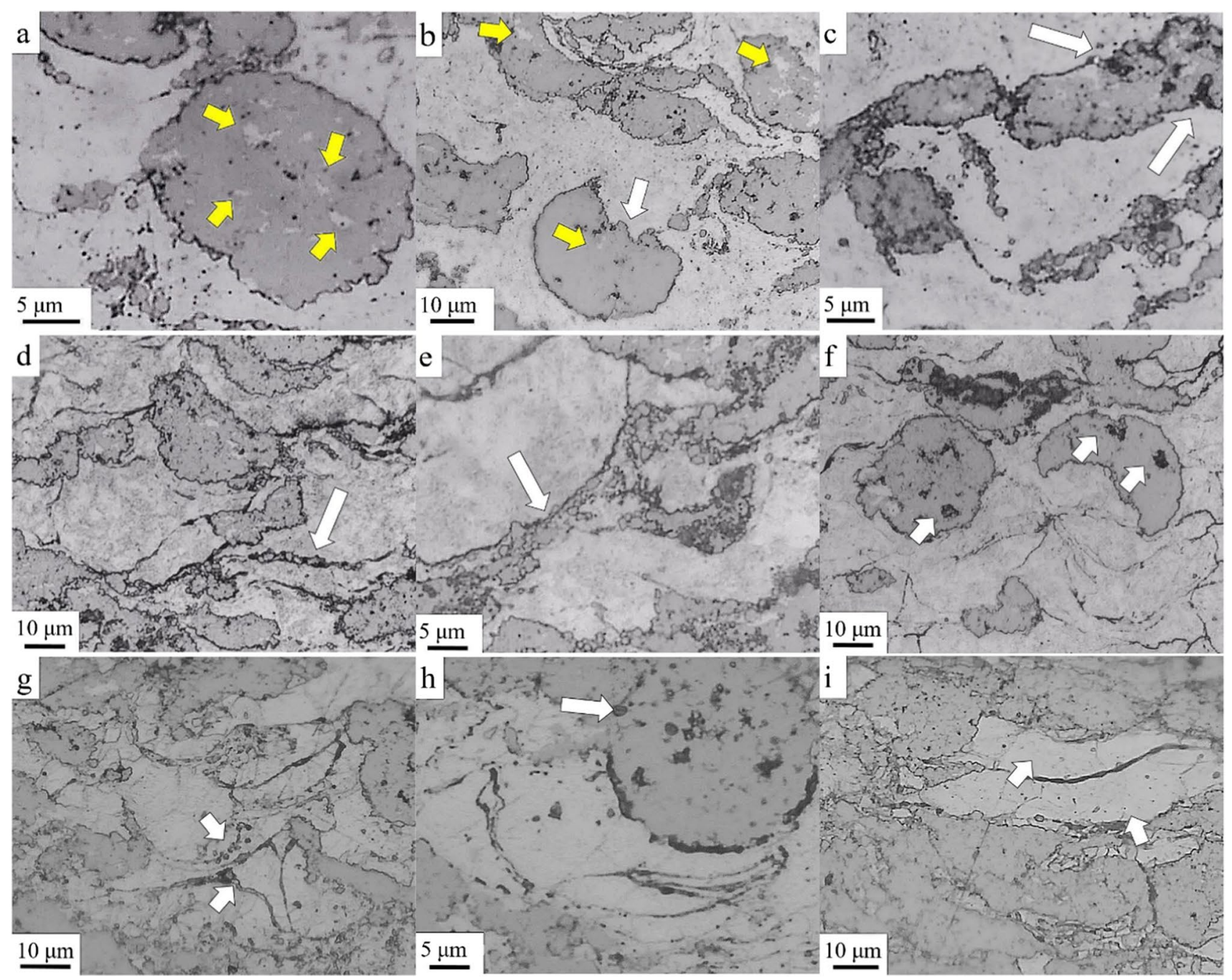

Fig. 4 Optical micrographs of the etched cold-sprayed composite coatings in different conditions. a-c AS, d-f HT1, and g-i HT2

In the first two cases, dispersed nickel islands can be found surrounded by the tungsten carbide agglomerations, as indicated by the yellow arrows in Fig. 4a and b. The WC particles cannot undergo plastic deformation, which is the main mechanism of porosity elimination. As a result, the brittle fracture of some carbides leads to their inhomogeneous distribution of porosity into the coating that preferably accumulates along the vicinity or the interior of tungsten carbide clusters (white arrows in Fig. 4c, f). Conversely, nickel particles exhibit significant deformation (Fig. 4i) that is fostered not only by the impact velocity at the moment of their deposition, but also by the hammering action of the hard ceramic particles that follow.

The microhardness values of the coatings were estimated at $335 \pm 68$ and $270 \pm 43$, and $255 \pm 34 \mathrm{HV} 0.3$ for the assprayed, HT1, and HT2 conditions, respectively. The two selected annealing routes led to a similar reduction of the coating microhardness. In the relevant literature[40, 44, 45], heat treatment applied to cold-sprayed coatings has been reported to alter the hardness depending on various factors such as the material, the heat treatment route, or the heat treatment technique that has been followed. More specifically, heat treatment may lead to coating densification via porosity elimination or microstructural transformations that could increase the coating hardness[40]. Conversely, hardness tends to drop when the annealing results in grain growth and reduction of the dislocation density[44]. The heat treatment indeed results in higher homogeneity of the coating; however, above a certain temperature, its beneficial impact is eliminated when it leads to microstructure coarsening[46]. In the current study, no phase transformation could be identified in the various conditions based on the results of optical and electron microscopy, and therefore, this factor will not be considered to interfere with the erosion performance of the coatings.

The recrystallization temperature $\left(T_{\mathrm{r}}\right)$ of pure nickel varies from 370 to $700{ }^{\circ} \mathrm{C}$ while it additionally depends on the holding time above the critical temperature as well as 
the amount of impurities[47]. In the case of cold-sprayed coatings, the high level of work hardening due to the cold spray process further lowered the $T_{\mathrm{r}}$ [48] which is below the selected holding temperature. As a result, partial or entire recrystallization of the nickel matrix is the main factor that contributed to the reduction of the hardness value in the heat-treated coatings. This factor overwhelmed the obtained densification of the coatings, while microstructural transformations were not found to attain a significant volume fraction in the heat-treated coating. Moreover, in the as-sprayed condition, the coating had a significant hardness inhomogeneity resulted from the non-uniform strain hardening of the particles upon impact[49]. In the current study, annealing also contributed to homogenization, as indicated by the substantially lower standard deviation of the hardness values in HT1 and HT2 conditions.

\subsection{Solid particle impingement erosion test}

\subsubsection{Analysis of DOE}

After the erosion experiments, the accumulative mass loss was used as the response to evaluate coatings' performance. The aggregated results, which are summarized in Table 3, were statistically analyzed using the RSM[35] and MINITAB ${ }^{\circledR}$ software.

The ANOVA table resulting from the RSM is shown in Table 4, while the main effect and the interaction plots are given in Fig. 5. It is evident from Fig. 5a that the angle is the most significant factor affecting mass loss. An angle of $90^{\circ}$ produces a mass loss of about $0.17 \mathrm{~g}$, while with an angle of $30^{\circ}$, the mass loss is slightly above $0.30 \mathrm{~g}$. At $60^{\circ}$, the mass loss is reduced to about $0.22 \mathrm{~g}$.

Despite that nickel is a ductile material, nickel coating, when produced with cold spray technique, can undergo low plastic deformation and exhibit brittle behavior due to the significant work hardening upon impact[50, 51]. Interestingly though, in all conditions, the coating did not follow the erosion behavior of brittle and ceramic materials that is increasing[7], until its final peak at $90^{\circ}$. There are many controversies in the relevant literature [52, 53] that indicate that the aforementioned trend cannot be used to explain the erosion behavior of the materials in all cases[54]. For instance, Sheldon and Finnie[55] reported that the type of erosion strongly depends on the erodent
Table 4 Analysis of variance (ANOVA) for mass loss (g), with the indication of the source of variation, degrees of freedom (DF), adjusted sum of squares (Adj SS), F-value, and p-value[35]

\begin{tabular}{lllcc}
\hline Source & DF & Adj SS & $F$-value & $p$-value \\
\hline$\alpha\left(^{\circ}\right)$ & 1 & 0.051300 & 145.15 & 0.000 \\
$\mathrm{C}$ & 2 & 0.003607 & 5.10 & 0.027 \\
$\alpha\left(^{\circ}\right)^{*} \alpha\left(^{\circ}\right)$ & 1 & 0.001270 & 3.59 & 0.085 \\
$\alpha\left(^{\circ}\right)^{*} \mathrm{C}$ & 2 & 0.001546 & 2.19 & 0.159 \\
Error & 11 & 0.003888 & - & - \\
Lack-of-fit & 2 & 0.002902 & 13.25 & 0.002 \\
Pure error & 9 & 0.000986 & - & - \\
Total & 17 & 0.061610 & - & - \\
\hline
\end{tabular}

size so that tiny erodents (below a threshold) can cause ductile mass removal even on brittle materials and a maximum erosion rate at oblique angles. Moreover, Beste et al. [56] mentioned that the size distribution of tungsten carbide particles as well as the binder percentage can significantly affect the erosion rate of cemented carbides and switch their erosion behavior from ductile to brittle mode and vice versa. This issue will be further discussed in Sect. 4.3.2 where the erosion features will be revealed in microscale.

Regarding the mass loss in the various coating conditions, it is equal to $0.24 \mathrm{~g}$ in the as-sprayed condition, it decreases to $0.21 \mathrm{~g}$ in HT1, and slightly increases in HT2. From qualitative analysis, the interaction between the two variables is evidenced in Fig. 5b, where parallel curves indicate no interaction, while the greater the deviation of the curves from the parallel state, the higher the degree of interaction[29]. At $30^{\circ}$, the heat treatment in both cases resulted in a lower average mass loss with respect to the as-sprayed condition. On the other hand, at $60^{\circ}$ and $30^{\circ}$, the average mass loss of as-sprayed conditions is located between the conditions HT2 and HT1. Indeed, at about $55^{\circ}$, the intersection of the AS and HT2 curves is observed. As shown in Table 4, all the variables are proved to be significant at an $\alpha$ risk of $10 \%$ (i.e., the corresponding $p$-values are less than $10 \%$ ), while the interaction between angle and condition was not found to be statistically significant at an $\alpha$ risk of $10 \%$.

The arrangement of the full factorial design, as shown in Table 3, allowed the identification of the appropriate

Table 3 Mass loss results of the DOE for the SPE tests after 10 min

\begin{tabular}{lllllllllllllllllll}
\hline Run order & 1 & 18 & 2 & 13 & 3 & 14 & 4 & 11 & 5 & 9 & 6 & 15 & 7 & 10 & 8 & 17 & 12 & 16 \\
\hline$a\left[^{\circ}\right]$ & 30 & & 90 & & 90 & & 60 & & 30 & & 60 & & 90 & & 60 & \\
C & AS & & HT1 & & HT2 & & AS & & HT2 & HT1 & & AS & & HT2 & HT1 \\
Mass loss (g) & 0.34 & 0.34 & 0.15 & 0.15 & 0.18 & 0.20 & 0.21 & 0.20 & 0.29 & 0.30 & 0.22 & 0.20 & 0.18 & 0.17 & 0.25 & 0.25 & 0.27 & 0.28 \\
\hline
\end{tabular}


Fig. 5 a Main effect plot and b interaction plot for mass loss $(\mathrm{g})$

\section{a}

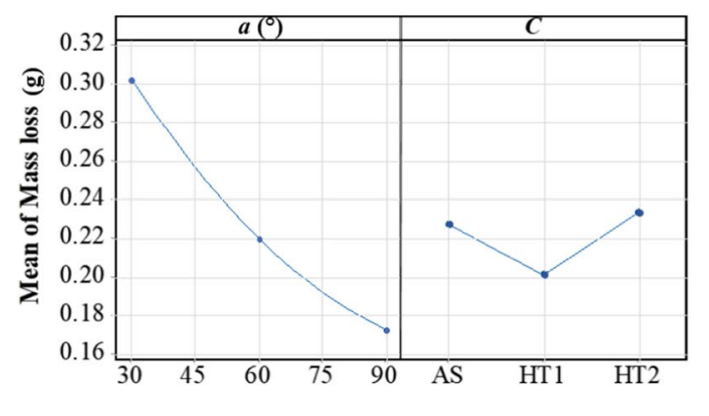

b

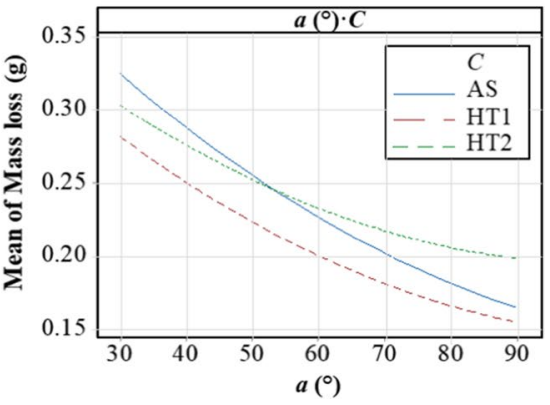

empirical equations, i.e., second-order regression equations. The standard stepwise regression was adopted to obtain models containing exclusively significant factors. The values of alpha-to-enter and alpha-to-remove were set to the standard value of $15 \%[57,58]$. Three regression models, one for each coating condition, were built to obtain a relationship with the mass loss and predict the erosion performance of future tests. The obtained regression models are reported in Eqs. (1), (2), and (3), respectively, for AS, HT1, and HT2 conditions.

$C=$ AS, Mass loss $(\mathrm{g})=0.4292-0.00455 \alpha\left({ }^{\circ}\right)+0.000020 \alpha\left({ }^{\circ}\right) \bullet \alpha\left({ }^{\circ}\right)$
A graph illustrating the three regression models (see Eqs. (1), (2), and (3)) is provided in Fig. 6.

The residual analysis for the model containing only significant factors (i.e., $\alpha\left(^{\circ}\right), \mathrm{C}$, and $\alpha\left({ }^{\circ}\right)^{*} \alpha\left(^{\circ}\right)$ ) was performed, both from a graphical and a quantitative point of view by plotting the residual plots (see Fig. 6) and by performing the Anderson-Darling test, showing that the residuals follow a normal distribution. The coefficient of determination, $R^{2}$, which is a goodness of fit measure of the model, reveals that the observed variation in the mass loss explained by the model is $91.18 \%$. Also, the $R^{2}$ predicted is very high[59], reaching $83.09 \%$.

$C=\mathrm{HT} 1$, Mass $\operatorname{loss}(\mathrm{g})=0.4026-0.00455 \alpha\left(^{\circ}\right)+0.000020 \alpha\left({ }^{\circ}\right) \cdot \alpha\left(^{\circ}\right)$

$C=\mathrm{HT} 2$, Mass $\operatorname{loss}(\mathrm{g})=0.4352-0.00455 \alpha\left(^{\circ}\right)+0.000020 \alpha\left({ }^{\circ}\right) \bullet \alpha\left({ }^{\circ}\right)$

Fig. 6 Representation of regression models for mass loss $(\mathrm{g})$, separately for each coating condition (AS, HT1, and HT2)

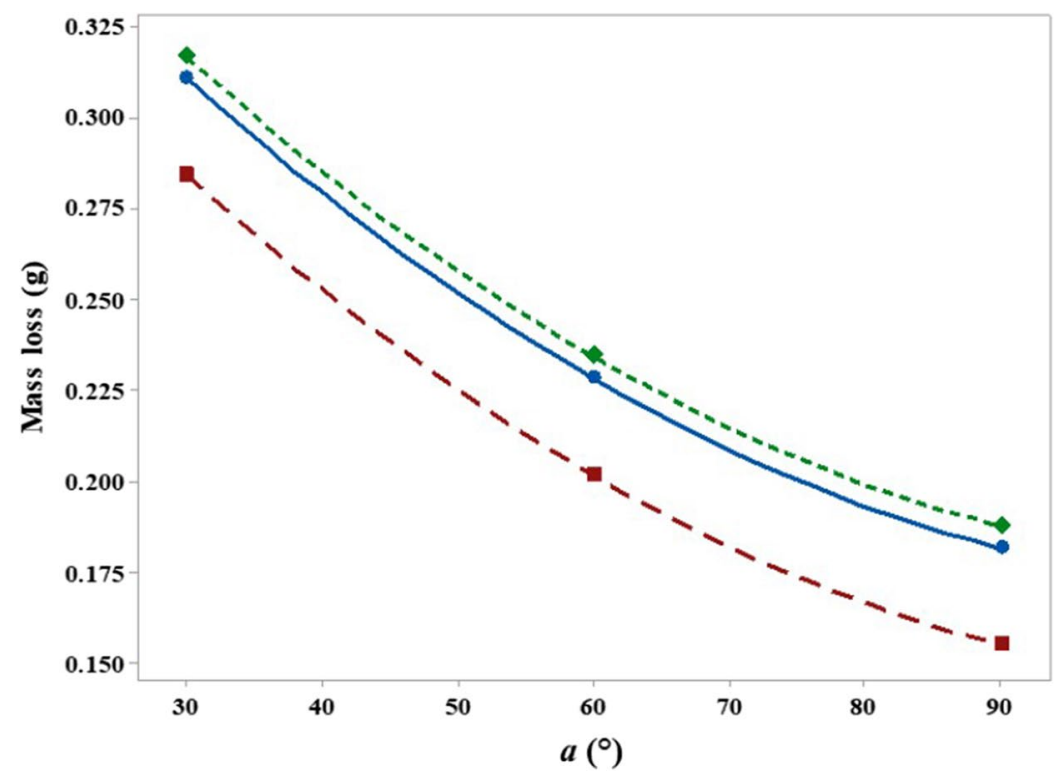


The adequacy of the regression models (1), (2), and (3) was tested by performing an experimental validation, whose results are reported in Table 5. Three additional coatings, one for each condition (AS, HT1, and HT2), were tested using an angle of $45^{\circ}$. In all three cases, measured mass loss is within the corresponding $95 \%$ confidence interval of the prediction, confirming the adequacy of the obtained models.

The regression curves may also be used to derive the combination of the variables minimizing the mass loss. In detail, the variables that minimize mass loss are an angle of $90^{\circ}$ and HT1 coating treatment. With this variables' setup, the predicted mass loss reaches $0.153 \mathrm{~g}$. It is interesting to observe that although the best combination of variables is an angle of $90^{\circ}$ and the heat-treated condition HT1, the use of heat treatment is particularly beneficial at low impact angles $\left(30^{\circ}\right)$. In fact, on average, both heat treatment cycles reduce mass loss compared to the as-sprayed condition by almost $20 \%$ in the case of HT1 and more than $14 \%$ in the case of HT2. On the contrary, at $60^{\circ}$ and $90^{\circ}$, only HT1 leads to lower mass loss compared to the as-sprayed condition.

As stated by Buszko et al.[60], there is significant interaction of the alumina particles that approach the eroded surface with those that rebound from it, while this phenomenon is higher at impact angles closer to $90^{\circ}$ [61]. This could be a factor that contributed to the general trend of the erosion rate decline with increasing the impact angle of the alumina particles. Moreover, based on the analysis authors followed, the heat treatment did not induce a significant statistical effect on the erosion performance of the composite nickel-tungsten carbide coating. Considering the fact that the erosion resistance of the materials generally increases with static hardness[7], the obtained hardness reduction of $47 \%$ in the coating after the heat treatment seems to counterbalance the positive effect of enhancement of the nickel matrix in terms of coherence and ductility. The main competitive mechanisms that relate to the coating conditions are coating densification (porosity elimination) and hardness reduction. The first prevails mainly at oblique angles, while its effect becomes less significant at angles closer to normal incidence. Overall, the HT1 coating attained the best

Table 5 Comparison between the actual (experimental) and the predicted (Eqs. 1-3) mass loss

\begin{tabular}{|c|c|c|c|}
\hline \multirow{2}{*}{$\begin{array}{l}\alpha\left({ }^{\circ}\right) \\
\mathrm{C}\end{array}$} & \multicolumn{3}{|l|}{45} \\
\hline & AS & HT1 & HT2 \\
\hline Measured mass loss (g) & 0.270 & 0.251 & 0.269 \\
\hline Predicted mass loss $(\mathrm{g})$ & 0.264 & 0.238 & 0.270 \\
\hline $\begin{array}{l}95 \% \text { confidence interval } \\
\text { of predicted mass loss } \\
\text { (g) }\end{array}$ & $0.243 ; 0.286$ & $0.217 ; 0.259$ & $0.249 ; 0.291$ \\
\hline Relative error (\%) & 2.3 & 5.5 & -0.4 \\
\hline
\end{tabular}

combination of porosity and hardness in all angles resulting in high erosion resistance, while holding temperature at $800{ }^{\circ} \mathrm{C}$ does not further decrease the erosion rate Fig. 7 .

\subsubsection{Analysis of the eroded areas}

The macrophotographs of the eroded surfaces are depicted in Fig. 8. All marks consist of a deep central zone where the primary erosion damage occurred, and the halo regions of the secondary zone, where the particle impact events were significantly fewer and resulted in surface roughening. The shape of the erosion scar is elliptical at the low impact angle of $30^{\circ}$ (Fig. 8a, d, g) and tends to become circular when the impact angle reaches $90^{\circ}$ (Fig. $8 \mathrm{c}, \mathrm{f}, \mathrm{i}$ ). Comparing the imprints in the three conditions, it can be observed that the heat treatment did not induce any significant variation in the surfacial area or the shape of the erosion marks. The erosion angle affected not only the shape of the erosion mark but also its surface area, which was found to increase with decreasing the impact angle. This can be a major reason that contributed to higher erosion rates at low impact angles.

Figure 9 depicts the topography of the erosion areas in each sample. In all cases, they present a U shape with a gradual transition of their depth from the lowest plane (black and purple) to the machined surface (orange and red areas). As recorded in all measurements, the maximum erosion depth was within the range of 553-921 $\mu \mathrm{m}$ and did not exceed the thickness (approximately $1 \mathrm{~mm}$ ) of the composite coating. This means that the erosion tests were exclusively performed on the coating and there was not any interference of the substrate with the alumina particles. In all coating conditions, the depth was lower when the impact angle was oblique $\left(30^{\circ}\right)$. This confirms that the maximization of mass loss at $30^{\circ}$ results mainly from the enlargement of the eroded area and not the deepening of it. Comparing erosion imprints at $60^{\circ}$ and $90^{\circ}$ (Fig. 9b-i), they differ slightly in terms of surface area, while it is not clear whether the erosion depth varies significantly.

The microscopic features of the erosion areas are indicatively depicted in Fig. 10. Overall, the coatings demonstrated different erosion characteristics in WC-enriched or WC-depleted areas. As expected, nickel was found to be more prone to removal and scooping compared to tungsten carbide-rich areas. Moreover, no significant differences in the erosion characteristics could be observed between the as-sprayed and the two heat-treated conditions. However, in the heat-treated samples, the erosion characteristics of the nickel matrix are more ductile (Fig. 10d-i), as indicated by their sharper topography compared to the assprayed samples. The alumina particles remove material in a small fraction of possible orientations and mainly with the formation of lips that are vulnerable against following impact of particles, while material removal through

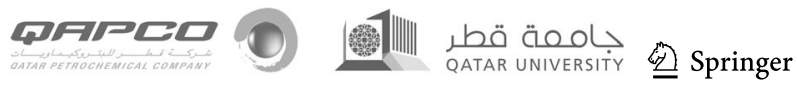



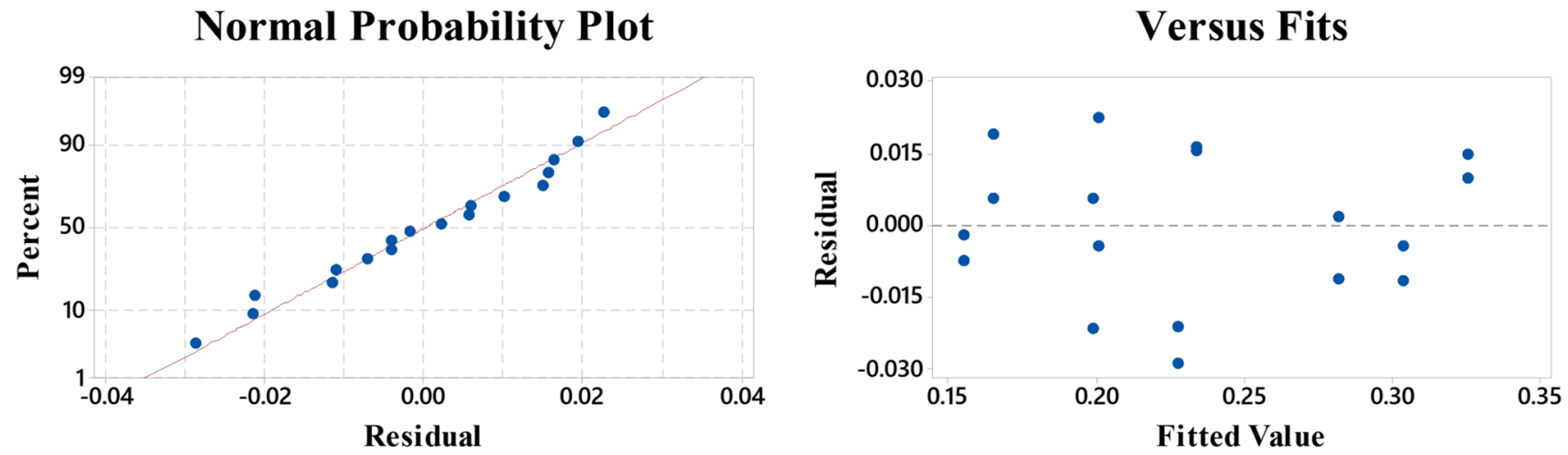

\section{Histogram}

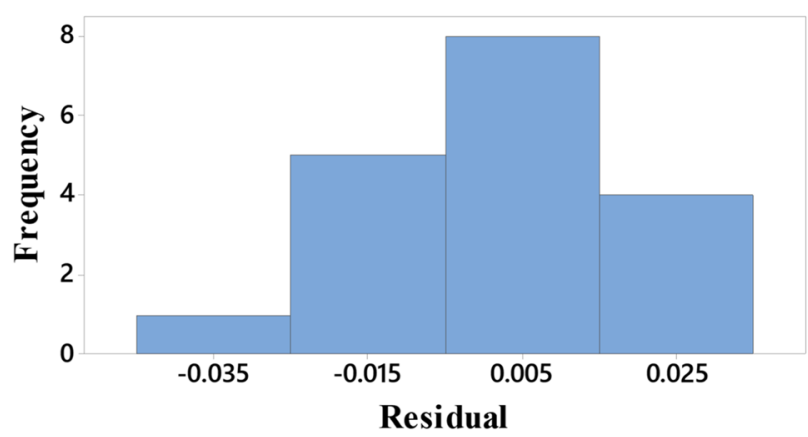

Fig. 7 Residual plots for hardness mass loss (g)

platelet formation mechanism was not identified as dominant (Fig. 10). The existence of WC nanoparticles prevented the platelet formation that is commonly fostered

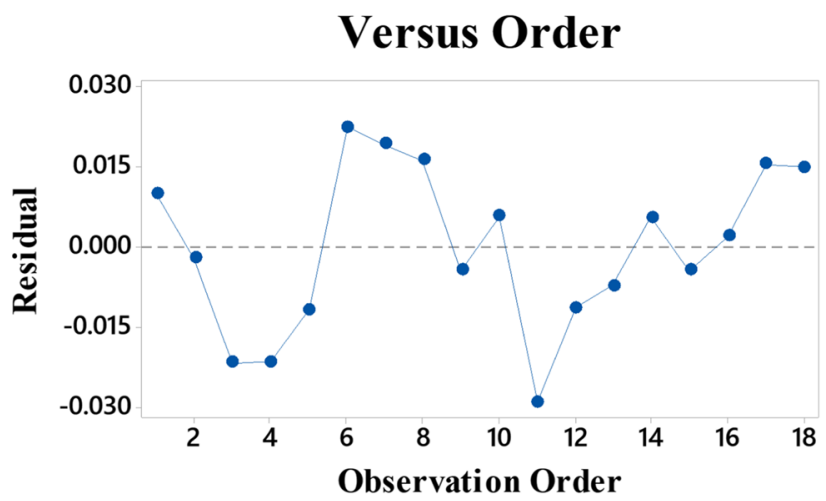

Fig. 8 The obtained imprints after $10 \mathrm{~min}$ of solid particle impingement erosion with alumina particles. a AS- $30^{\circ}, \mathbf{b}$ AS- $60^{\circ}$, c AS $-90^{\circ}$, d HT 1 $30^{\circ}$, e HT1- $60^{\circ}$, f HT $1-90^{\circ}$, g HT2 $-30^{\circ}$, h HT2 $-60^{\circ}$, i HT2- $90^{\circ}$
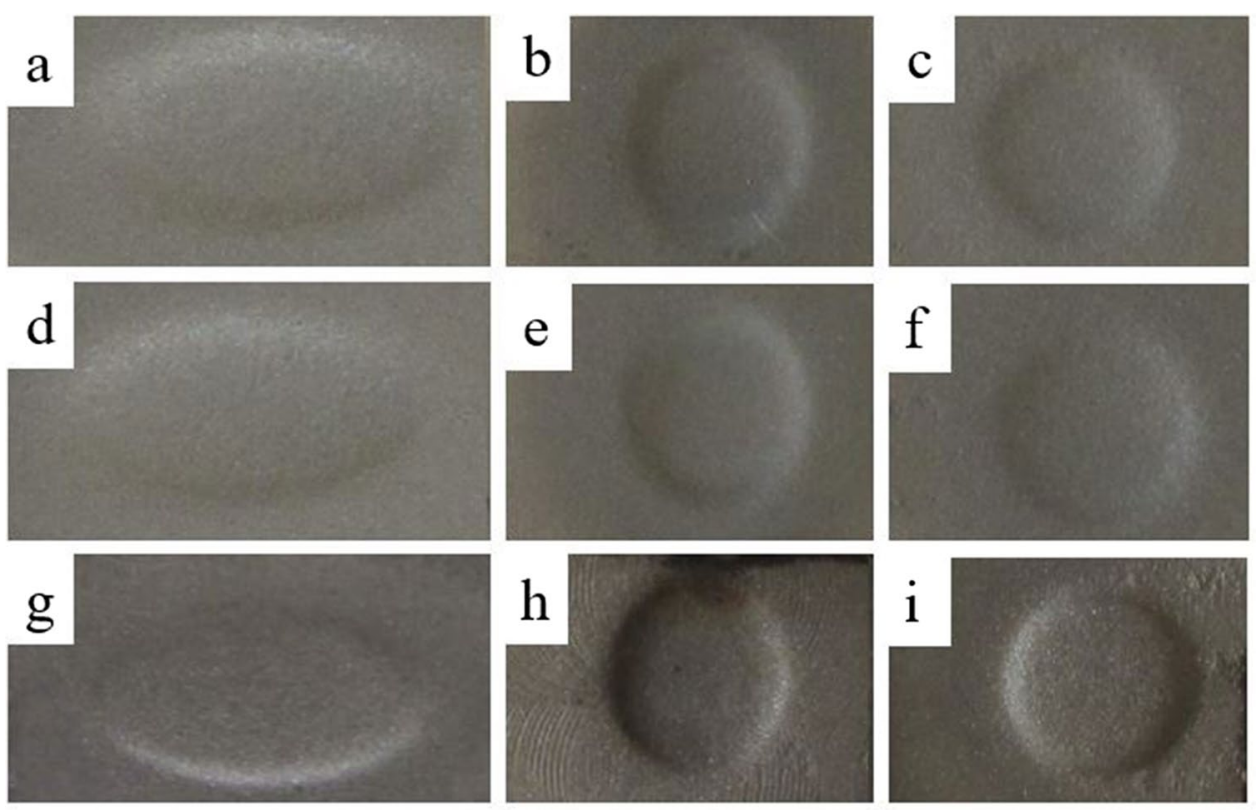

$10 \mathrm{~mm}$ 


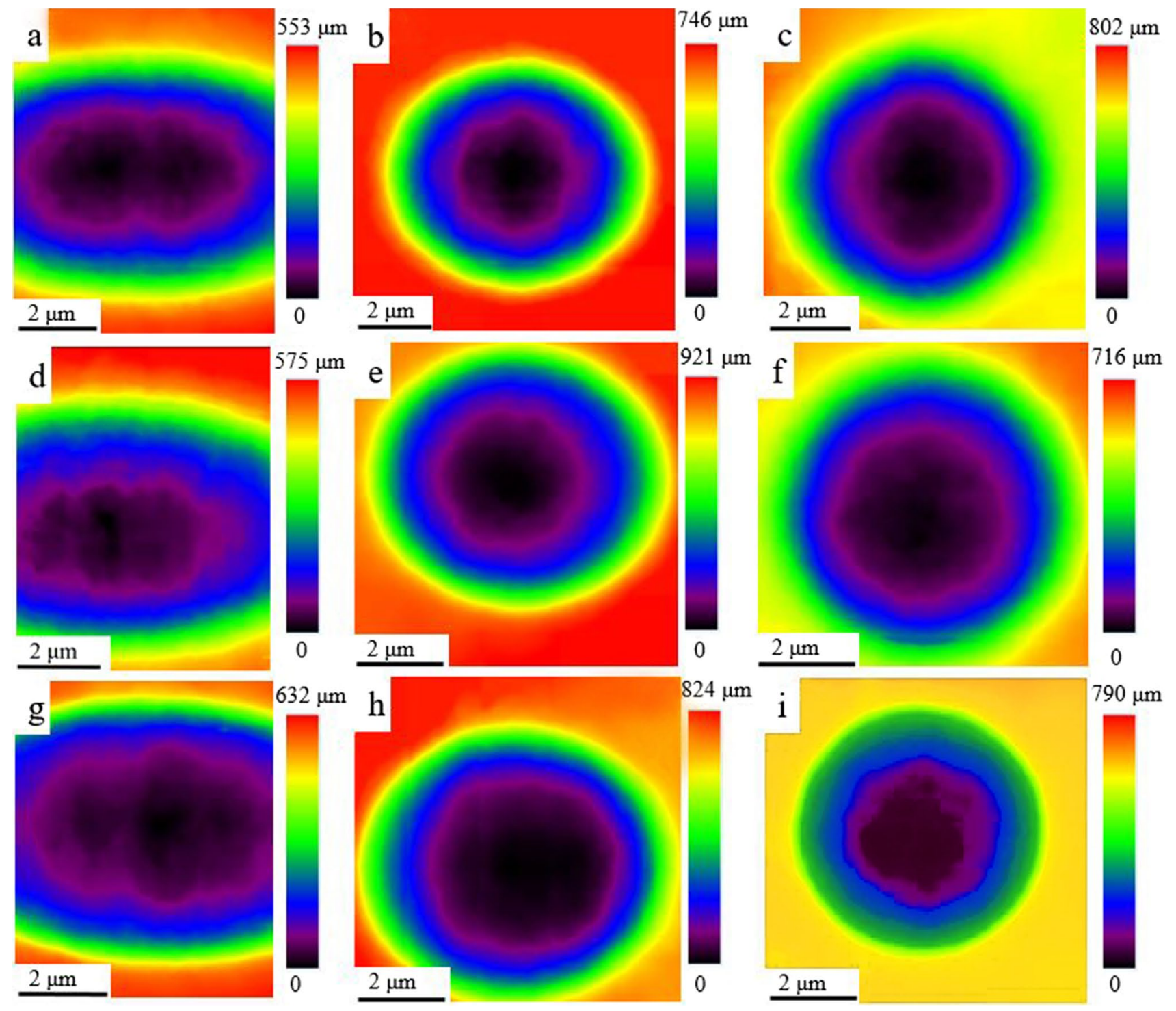

Fig. 9 Optical images of the erosion marks on the surface of the samples. a AS- $30^{\circ}$, b AS $-60^{\circ}$, c AS $-90^{\circ}, \mathbf{d ~ H T 1}-30^{\circ}$, e HT1- $60^{\circ}$, f HT $1-90^{\circ}, \mathbf{g ~ H T} 2-30^{\circ}, \mathbf{h} \mathrm{HT} 2-60^{\circ}$, i HT2- $90^{\circ}$

of magnitude smaller than the alumina particles (see also Fig. 2d, e).

At the low impingement angle $\left(30^{\circ}\right)$ where the erosion rate is higher (Fig. 5a), ploughing is the major mechanism of material removal. Alumina particles slide while scratching the nickel matrix (Fig. 10a, d, g). Areas with high percentage of tungsten carbides tend to deform under the repetitive impact of the erodent particles while creating irregular erosion morphology characterized by concavities and protrusions. Figure 10d presents such a case where the coating shows significant surface retention of the carbides without the accompaniment of clear indentations. In HT2 condition, microcutting was observed to be the secondary material removal mechanism as indicated in Fig. 10g where pits with prismatic shape and clear contours are obvious resulted from the penetration of the erodents. At an impact angle of $60^{\circ}$ (Fig. 10b, e, h), microcutting seems to be more intense and prevails over ploughing action. The coatings exhibited pits, grooves, and craters. The striations as shown in Fig. 10b were formed on the nickel matrix either as a replica of the erodents that may carry wave-like undulations or due to the repetitive impact of their sharp edges (see also Fig. 2c). Formation of striations on alumina particle (Fig. 10c) as well as nickel (Fig. 10i) was also observed at an impact angle of $90^{\circ}$. In this case, irregular smeared indentations appear on the coating erosion surface (Fig. 10c). Although the impact of the alumina may locally flatten the nickel particles (Fig. 10c), platelet formation is restricted, as previously mentioned. Microcutting is the main material removal mechanism, accompanied by the formation of 


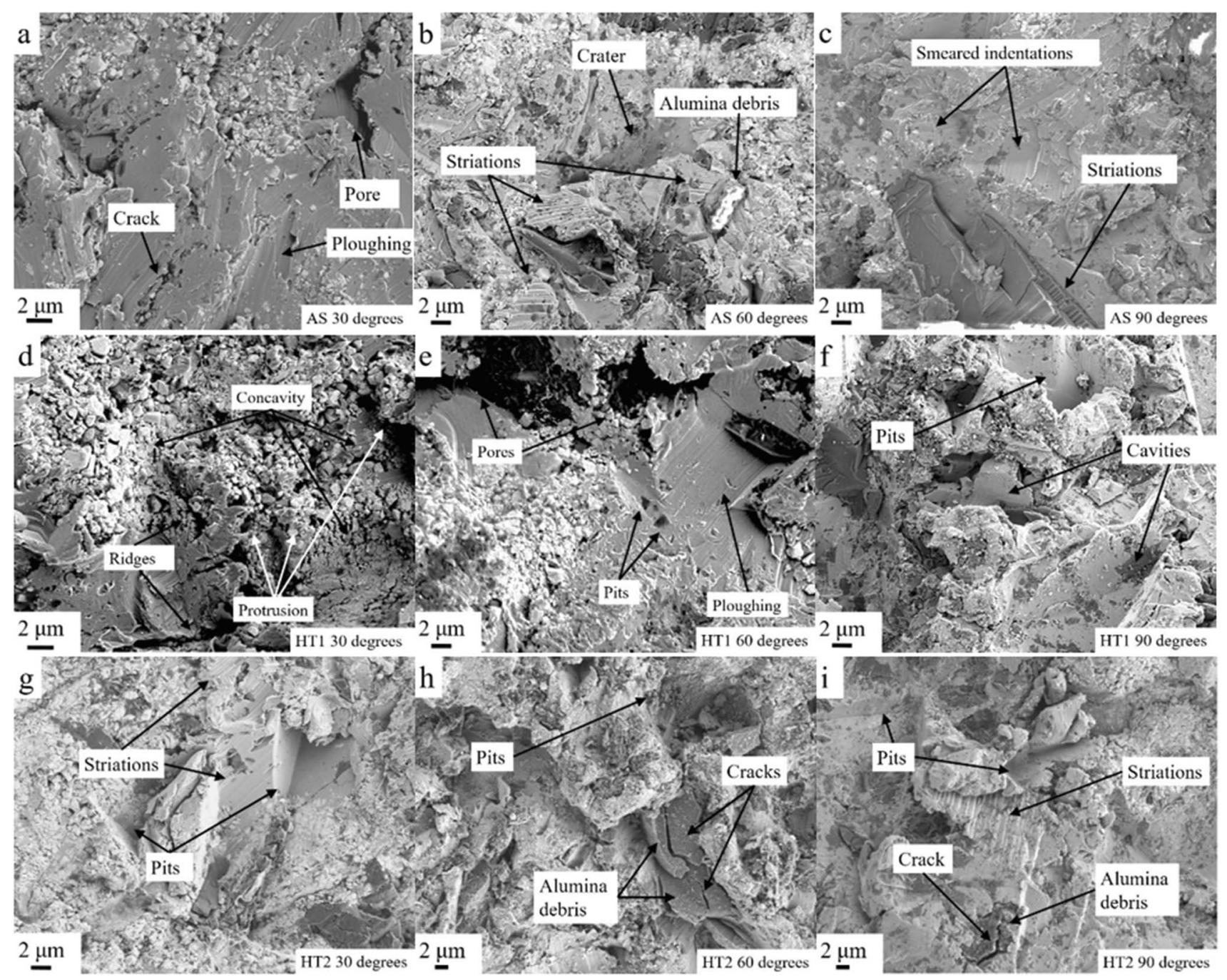

Fig. $10 \mathrm{SEM}$ images of the erosion areas of the WC/Ni coatings: a AS $-30^{\circ}, \mathbf{b} \mathrm{AS}-60^{\circ}, \mathbf{c} \mathrm{AS}-90^{\circ}, \mathbf{d} \mathrm{HT} 1-30^{\circ}, \mathbf{e ~ H T 1}-60^{\circ}, \mathbf{f ~ H T} 1-90^{\circ}, \mathbf{g}$

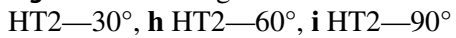

deep and sharp cavities, especially in the heat-treated coating (Fig. 10f). Finally, the retention of cracked alumina particles was observed in eroded coatings under an impact angle of $60^{\circ}$ and $90^{\circ}$ (see Fig. 10h, i). On the contrary, at $30^{\circ}$, the erodents are more likely to impinge and rebound without being capable to consolidate into the coating.

\section{Conclusions}

This study investigated the annealing effect on the solid particle erosion resistance of cold-sprayed WC/Ni coating. The main conclusions can be summarized as follows:

- The annealing contributed to porosity elimination with an enhancement of the nickel matrix coherence and reduction of its hardness. These are the main competi- tive mechanisms that affect the erosion resistance of the composite coating.

- Impact angle was a more influential factor in the erosion rate than heat treatment. In all cases, the erosion rate decreased with increasing erosion angle.

- The effect of impact angle and condition of coating resulted in being statistically significant at an $\alpha$ risk of $10 \%$ on the mass loss, as well as the quadratic effect of the angle. On the contrary, the interaction between angle and coating condition was found not to be statistically significant.

- Heat treatments appear to increase erosion resistance for impact angles below $55^{\circ}$, while in higher angles, holding temperature of $800{ }^{\circ} \mathrm{C}$ facilitates material removal due to hardness reduction.

- Three regression models that relate the impact angle and the mass loss, separately for as-sprayed and the

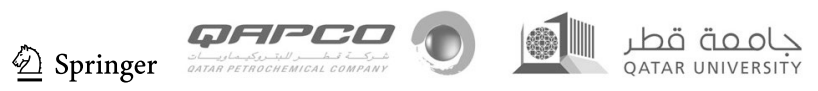


two heat-treated conditions, were built for prevision and optimization purposes. It was found that when the coating is in the HT1 condition (holding temperature of $600^{\circ} \mathrm{C}$ ) and the erosion angle is at $90^{\circ}$, the material loss is minimum.

- The adequacy of the three models was confirmed through an experimental validation consisting of three additional tests in which an angle of $45^{\circ}$ was used.

- Microscopic examination of the erosion surfaces revealed ploughing and microcutting to be the main material removal mechanism. The first prevails at $30^{\circ}$ while the latter at $90^{\circ}$.

Acknowledgements The authors would like to thank the CRANN Advanced Microscopy Laboratory (AML) of Trinity College Dublin for its assistance in the section of microscopy.

Funding Open Access funding provided by the IReL Consortium. This work received finacial support from Enterprise Ireland (EI) and SchuF Valve Technology GmbH (IP2018 0730).

\section{Declarations}

Conflict of interest The authors declare no competing interests.

Open Access This article is licensed under a Creative Commons Attribution 4.0 International License, which permits use, sharing, adaptation, distribution and reproduction in any medium or format, as long as you give appropriate credit to the original author(s) and the source, provide a link to the Creative Commons licence, and indicate if changes were made. The images or other third party material in this article are included in the article's Creative Commons licence, unless indicated otherwise in a credit line to the material. If material is not included in the article's Creative Commons licence and your intended use is not permitted by statutory regulation or exceeds the permitted use, you will need to obtain permission directly from the copyright holder. To view a copy of this licence, visit http://creativecommons.org/licenses/by/4.0/.

\section{References}

1. Papyrin, A., Kosarev, V., Klinkov, S., Alkhimov, A. \& Fomin, V. Cold Spray Technology. (Elsevier, 2007).

2. Karthikeyan, J. The advantages and disadvantages of the cold spray coating process. in The cold spray materials deposition process: Fundamentals and applications (2007).

3. W. Li et al., Solid-state additive manufacturing and repairing by cold spraying: A review. J. Mater. Sci. Technol. 34, 440-457 (2018)

4. Pattison, J., Celotto, S., Morgan, R., Bray, M. \& O’Neill., W. Cold gas dynamic manufacturing: A non-thermal approach to freeform fabrication. Int. J. Mach. Tools Manuf. 47, 627-634 (2007).

5. N.M. Melendez, V.V. Narulkar, G.A. Fisher, A.G. McDonald, Effect of reinforcing particles on the wear rate of low-pressure cold-sprayed WC-based MMC coatings. Wear 306, 185-195 (2013)

6. R. Fernandez, B. Jodoin, Cold Spray Aluminum-Alumina Cermet Coatings: Effect of Alumina Morphology. J. Therm. Spray Technol. 28, 737-755 (2019)
7. ASM International. ASM Handbook, Volume 18: Friction Lubrication and Wear Technology. (ASM International, 2018).

8. C.P. Paul, S.K. Mishra, P. Tiwari, L.M. Kukreja, Solid-Particle Erosion Behaviour of WC/Ni Composite Clad layers with Different Contents of WC Particles. Opt. Laser Technol. 50, 155-162 (2013)

9. S. Dosta, M. Couto, J.M. Guilemany, Cold spray deposition of a WC-25Co cermet onto A17075-T6 and carbon steel substrates. Acta Mater. 61, 643-652 (2013)

10. T.B. Torgerson et al., Room and elevated temperature sliding wear behavior of cold sprayed Ni-WC composite coatings. Surf. Coatings Technol. 350, 136-145 (2018)

11. M. Szala, L. Łatka, M. Walczak, M. Winnicki, Comparative Study on the Cavitation Erosion and Sliding Wear of Cold-Sprayed Al/ $\mathrm{A} 12 \mathrm{O} 3$ and $\mathrm{Cu} / \mathrm{Al} 2 \mathrm{O} 3$ Coatings, and Stainless Steel, Aluminium Alloy Copper and Brass. Metals (Basel) 10, 1-25 (2020)

12. Kazasidis, M. et al. Microstructure and cavitation erosion performance of nickel-Inconel 718 composite coatings produced with cold spray. Surf. Coatings Technol. 382, (2020).

13. M. Couto, S. Dosta, J.M. Guilemany, Comparison of the mechanical and electrochemical properties of WC-17 and 12Co coatings onto Al7075-T6 obtained by high velocity oxy-fuel and cold gas spraying. Surf. Coatings Technol. 268, 180-189 (2015)

14. K.I. Triantou, D.I. Pantelis, V. Guipont, M. Jeandin, Microstructure and tribological behavior of copper and composite copper+alumina cold sprayed coatings for various alumina contents. Wear 336-337, 96-107 (2015)

15. S. Yin, E.J. Ekoi, T.L. Lupton, D.P. Dowling, R. Lupoi, Cold spraying of WC-Co-Ni coatings using porous WC-17Co powders: Formation mechanism, microstructure characterization and tribological performance. Mater. Des. 126, 305-313 (2017)

16. S. Krebs, F. Gaertner, T. Klassen, Cold spraying of Cu-Al-Bronze for cavitation protection in marine environments. Materwiss. Werksttech. 45, 708-716 (2014)

17. Szala, M. \& Hejwowski, T. Cavitation Erosion Resistance and Wear Mechanism Model of Flame-Sprayed Al2O3-40\%TiO2/ NiMoAl Cermet Coatings. Coatings 8, (2018).

18. R. Silverstein, O. Sobol, T. Boellinghaus, W. Unger, D. Eliezer, Hydrogen behavior in SAF 2205 duplex stainless steel. J. Alloys Compd. 695, 2689-2695 (2017)

19. A. Patnaik, A. Satapathy, N. Chand, N.M. Barkoula, S. Biswas, Solid particle erosion wear characteristics of fiber and particulate filled polymer composites: A review. Wear 268, 249-263 (2010)

20. Swain, B., Swadhin, P., Priyabrata, M., Mohapatra, S. \& Behera, A. Solid particle erosion wear of plasma sprayed NiTi alloy used for aerospace applications. in ITSC, Proceedings of the International Thermal Spray Conference (ASM International, 2019).

21. J.R.T. Branco, R. Gansert, S. Sampath, C.C. Berndt, H. Herman, Solid particle erosion of plasma sprayed ceramic coatings. Mater. Res. 7, 147-153 (2004)

22. Y. Lian, Y. Li, Investigation on erosion resistance of WC-Co-Cr coatings. Tribol. Online 13, 36-42 (2018)

23. Ahmad Alidokht, S., Vo, P., Yue, S. \& Chromik, R. R. Erosive wear behavior of Cold-Sprayed Ni-WC composite coating. Wear 376-377, 566-577 (2017).

24. S.A. Alidokht, J. Lengaigne, J.E. Klemberg-Sapieha, S. Yue, R.R. Chromik, Effect of Microstructure and Properties of Ni-WC Composite Coatings on Their Solid Particle Erosion Behavior. J. Mater. Eng. Perform. 28, 1532-1543 (2019)

25. V.R. Kiragi, A. Patnaik, T. Singh, G. Fekete, Parametric optimization of erosive wear response of TiAlN-coated aluminium alloy using Taguchi method. J. Mater. Eng. Perform. 28, 838-851 (2019)

26. S. Alidokht, P. Vo, S. Yue, R.R. Chromik, Erosive wear behavior of Cold-Sprayed Ni-WC composite coating. Wear 376-377, 566-577 (2017) 
27. S. Sahu, A. Satapathy, A. Patnaik, K.P. Sreekumar, P.V. Ananthapadmanabhan, Development, characterization and erosion wear response of plasma sprayed fly ash - aluminum coatings. Mater. Des. 31, 1165-1173 (2010)

28. M. Parsi et al., Journal of Natural Gas Science and Engineering A comprehensive review of solid particle erosion modeling for oil and gas wells and pipelines applications. 21, 850-873 (2014)

29. Montgomery, D. C. Design and analysis of experiments. (John Wiley \& Sons, 2017).

30. A.S. Praveen, J. Sarangan, S. Suresh, B.H. Channabasappa, Optimization and erosion wear response of $\mathrm{NiCrSiB} / \mathrm{WC}-\mathrm{Co} \mathrm{HVOF}$ coating using Taguchi method. Ceram. Int. 42, 1094-1104 (2016)

31. S.P. Sahu, A. Satapathy, A. Patnaik, K.P. Sreekumar, P.V. Ananthapadmanabhan, Development, characterization and erosion wear response of plasma sprayed fly ash-aluminum coatings. Mater. Des. 31, 1165-1173 (2010)

32. Wang, D. et al. Micro-nano multilayer structure design and solid particle erosion resistance performance of $\mathrm{CrAlNx} / \mathrm{CrAlN}$ coating. Vacuum 172, 109064 (2020).

33. X. Cao et al., Sand particle erosion resistance of the multilayer gradient TiN/Ti coatings on Ti6Al4V alloy. Surf. Coatings Technol. 365, 214-221 (2019)

34. H.X. Hu, S.L. Jiang, Y.S. Tao, T.Y. Xiong, Y.G. Zheng, Cavitation erosion and jet impingement erosion mechanism of cold sprayed Ni-Al2O3 coating. Nucl. Eng. Des. 241, 4929-4937 (2011)

35. Montgomery, D. C., Runger, G. C. \& Hubele, N. F. Engineering statistics. (20011).

36. N.M. Melendez, A.G. McDonald, Development of WC-based metal matrix composite coatings using low-pressure cold gas dynamic spraying. Surf. Coatings Technol. 214, 101-109 (2013)

37. S.A. Alidokht, P. Manimunda, P. Vo, S. Yue, R.R. Chromik, Cold spray deposition of a Ni-WC composite coating and its dry sliding wear behavior. Surf. Coatings Technol. 308, 424-434 (2016)

38. T. Peat et al., Enhanced erosion performance of cold spray codeposited AISI316 MMCs modified by friction stir processing. Mater. Des. 120, 22-35 (2017)

39. W. Li, H. Assadi, F. Gaertner, S. Yin, A Review of Advanced Composite and Nanostructured Coatings by Solid-State Cold Spraying Process. Crit. Rev. Solid State Mater. Sci. 44, 109-156 (2019)

40. J. Tang et al., Effects of Post-spray Heat Treatment on Hardness and Wear Properties of Ti-WC High-Pressure Cold Spray Coatings. J. Therm. Spray Technol. 27, 1153-1164 (2018)

41. W. Sun et al., Improving microstructural and mechanical characteristics of cold-sprayed Inconel 718 deposits via local induction heat treatment. J. Alloys Compd. 797, 1268-1279 (2019)

42. W. Wong et al., Cold spray forming of Inconel 718. J. Therm. Spray Technol. 22, 413-421 (2013)

43. D. Levasseur, S. Yue, M. Brochu, Pressureless sintering of cold sprayed Inconel 718 deposit. Mater. Sci. Eng. A 556, 343-350 (2012)

44. Sun, W. et al. Post-process treatments on supersonic cold sprayed coatings: A review. Coatings 10, (2020).

45. Yu Sang Ji, Kim H.H., Oh Hyun Ik, L. K. A. Densification and Purification of Cold Sprayed Ti Coating Layer by Using
Annealing in Different Heat Treatment Environments. Adv. Mater. Res. (2012). https://doi.org/10.4028/www.scientific.net/AMR. 602-604.1604

46. X. Qi, C. Wang, R. Zhang, M. Han, Effect of Heat Treatment on Microstructure and Performance of Nano-WC Particle-Strengthened Ni Composite Coatings by Electrobrush Plating. J. Mater. Eng. Perform. 29, 8122-8129 (2020)

47. Mitchell, B. S. Materials Engineering and Science an Introduction To Materials Engineering and Science for Chemical and Materials Engineers. (2014).

48. A. Bhaduri, Mechanical Properties and Working of Metals and Alloys. Smithells Metals Reference Book (2003). https://doi.org/ 10.1016/B978-075067509-3/50025-7

49. M.R. Rokni, S.R. Nutt, C.A. Widener, V.K. Champagne, R.H. Hrabe, Review of Relationship Between Particle Deformation, Coating Microstructure, and Properties in High-Pressure Cold Spray. J. Therm. Spray Technol. 26, 1308-1355 (2017)

50. S. Yin et al., Cold spray additive manufacturing and repair: Fundamentals and applications. Addit. Manuf. 21, 628-650 (2018)

51. A. Moridi, S.M. Hassani-Gangaraj, M. Guagliano, M. Dao, Cold spray coating: review of material systems and future perspectives. Surf. Eng. 30, 369-395 (2014)

52. El-Domiaty, A., Abd el-Hafez, H. M. \& Shaker, M. A. Drilling of glass sheets by abrasive jet machining. World Acad. Sci. Eng. Technol. 56, 61-67 (2009).

53. Kleis, I. \& Kulu, P. Solid Particle Erosion. Friction, Wear, and Erosion Atlas (2013). https://doi.org/10.1201/b15984-10

54. Zum Gahr, K.-H. Microstructure and Wear of Materials. Journal of the Society of Materials Science, Japan 37, 16 (1988).

55. G.L. Sheldon, I. Finnie, On the Ductile Behavior of Nominally Brittle Materials During Erosive Cutting. J. Eng. Ind. 88, 387-392 (1966)

56. U. Beste, L. Hammerström, H. Engqvist, S. Rimlinger, S. Jacobson, Particle erosion of cemented carbides with low Co content. Wear 250-251, 809-817 (2001)

57. Myers, R. H. \& Montgomery, D. C. Response surface methodology: process and product optimization using designed experiments. 4, (John Wiley \& Sons, 1995).

58. Verna, E. et al. Modeling of erosion response of cold-sprayed In718-Ni composite coating using full factorial design. Coatings 10, (2020).

59. Devore, J. L. Probability and Statistics for Engineering and the Sciences. (Cengage learning, 2011).

60. M.H. Buszko, A.K. Krella, An Influence of Factors of Flow Condition, Particle and Material Properties on Slurry Erosion Resistance. Adv. Mater. Sci. 19, 28-53 (2019)

61. Laguna-Camacho, J. R., Gallardo-Hernandez, E. A. \& Vera-Cardenas, E. E. Solid Particle Erosion on Different Metallic Materials, Tribiology in Engineering. 63-78 (2013). https://doi.org/10.5772/ 51176

62. Bergmann, C. \& Vincenzi, J. Protection against Erosive Wear Using Thermal Sprayed Cermet: A review. (Springer, 2011). 